\title{
IMPACT OF MOTIVATIONAL INTERVIEWING ON ATTITUDE AND BEHAVIOURALOUTCOME OF INTERNET GAMING ADDICTION (IGA) AMONG ADOLESCENTS.
}

\author{
Ms. Rawindar Kaur* | Dr. Ramandeep Kaur Dhillon** \\ *Ph.D. Scholar, Himalayan University, Itanagar, Arunachal Pradesh, India. \\ ${ }^{* *}$ Research Supervisor, Himalayan University, Itanagar, Arunachal Pradesh, India. \\ DOI: http://doi.org/10.47211/idcij.2021.v08i03.009
}

\begin{abstract}
:
OBJECTIVE: To assess the impact of motivational interviewing on attitude and behavioural outcome among adolescents regarding IGA at selected schools of Patiala city of Punjab.

METHODS: This was an experimental research design with two group pre-test post-test control group design. The samples were recruited by opting probability sampling technique. The study samples were the adolescents with age group of 15 to 18 years old who have met the eligibility criteria. Total 300 adolescents were recru ited based on power analysis. The research instruments were the StructuredAttitude Rating Scale on IGA (SARSIGA) and Structured Behavioural Outcome check list on IGA (SBOC-IGA). The collected data were organised logically and data was analysed by SPSS-22.

RESULTS: The mean difference of experimental group was 18.89 while in control group it was 2.96. F ratio identified as 10.10 which reflected that among both the group, there is significant difference in terms of attitude of adolescents regarding internet gaming addiction. The mean difference of experimental group was 12.80 while in control group it was 4.27. F ratio identified as 10.40 which reflected that among both the group, there is significant difference in terms of behavioural outcome of adolescents regarding internet gaming addiction. The finding suggested that the provided motivational interviewing technique is effective to enh ance attitude and behavioural outcome of IGA victims.

CONCLUSION: findings of the study suggested that internet gaming disorder or dependency has reached to significant level and motivational interviewing is helping adolescents to improve their attitudes and en hanced their behaviour outcome regarding internet gaming disorders.
\end{abstract}

KEYWORDS: internet gaming disorder, motivational interviewing, adolescents.

\section{ABOUT AUTHORS:}

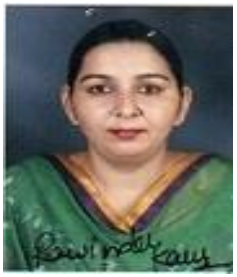

Author Ms. Rawindar Kaur is Ph.D. Scholar at Himalayan University, Itanagar, Arunachal Pradesh, India \& Nursing Officer, MKH Hospital Patiala Punjab, India.

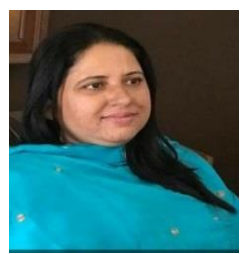

Author Dr. RamandeepKaur Dhillon is Research Guide at Himalayan University, Itanagar, Arunachal Pradesh, India. 


\section{INTRODUCTION:}

Internet considered as one of extraordinary innovation of people, since it made things simple and the information recovery is so $\mathrm{OK}$ with the assistance of web. It improved the information on in dividuals which they utilized in everyday life. Existing electronic games or web playing are tremendously affecting existence of individuals in present period. As this century considered as innovation driven century where innovation will be at driving seat and every individual needs to run over with it. At the point when we talk about then there will be a serious high number of positive variables examined yet every coin has two sections, likewise this innovation additionally have some of negative focuses.(1)

The telecom innovation has made our life so basic and advantage ous that it is assisting individuals with living easily and speak with relatives, companions, experts, partners and designated crowd at very simplicity level. At the point when we watch out for it then we will understand that mobile phones particularly of keen classification and online world has had gigantic effect.(2) As per National Centre of Education Statistic preliminary studies at America has concluded that the adolescents aged 5 to 17 yearsare accessing inter net services in very young age and a very high number among these users are involved in internet gaming. (3)

The Diagnostic and Statistical Manual of Mental Disorders (DSM-V) will come to fruition as the American Psychiatric Association accepted to include Internet use disorder as mental health problem worthy of fur ther scientific investigation. The over-the-toputilization of the Internet has been connected to an assortment of negative psychosocial results.(4) Gaming disorder is defined in the 11th Revision of the International Classification of Diseases (ICD-11) as a pattern of gaming behaviour ("digital-gaming" or "video-gaming") characterized by impaired control over gaming, increasing priority given to gaming over other activities to the extent that gaming takes precedence over other interests and daily activities, and continuation or escalation of gaming despite the occurrence of negative consequences.(5)

Various elements assume a crucial part in the effect of computer games on a person. A portion of the effects are for genuine, for example, upset rest designs, similar to abstain from food issues, similar to an insufficiency in the active work while some are potential. Somewhat certain gamers don't see their propensity for gaming as a danger to their physical or mental prosperity. Though some gamers recognize their falling apart public activity as a notable endowment of steady gaming. Certain examinations de monstrate that gaming has been a most loved break technique from the truth and stressors of day-by-daylife. (6)

Psychological factors such as using internet to escape from self-dissatisfaction, to deal with stress, e motional regulation along with individual temperaments are the strands in connection with solid association with enhancing condition of internet gaming addiction and high-riskbehaviours among adolescents. This same study found that owning a personal device, use of smart phones, browsing, craze of social media friends hip, online purchasing, web series, online play was significantly associated with internet addictions.(7)

The Ml treatment is advising treatment in which the individual will be controlled to move towards for tify of own to defeat from the habit. Devotion, responsibility and assurance are three essential mainstays of Inspirational talking strategy. System of this treatment is chipping away at example of engagingthe custo mer to bring wanted changes and become director for claims movement. This treatment is working when individual is resolved to make changes in their dependent conduct in light of the fact that the ne cessary adjustment comes from the inside so comprehend that the individual the person in question is totally prepared for conduct alteration. (8)

The internet gaming compulsion is very comparative with different addictions like substance habit. Additionally, as other habit the web-based gaming enslavement is likewise a dilige nt, broad and rehashed scenes of utilizing internet gaming administrations which have huge connection with compromised existence with family, companions, and relative and hel pless work execution.(9)

There is a new flood and pattern in on the web and disconnected computer games and particularly fight games. Since the beginning of these games fundamentally two assessments have continually begun with it one is there are unsafe results of playing videogames on the web and second is computer games assist the per son with adapting up to specific stressors throughout everyday life. Therefore, this study designed by researcher to plan out and visualize the impact of motivational interviewing technique on attitude and behavioural outcome of adolescents suffe ring with Internet gaming dependency.

MATERIALS AND METHODS:

This study identified following objectives to investigate:

1. To assess the pre- and post-intervention attitude among adolescents in line with IGA.

2. To assess the pre- and post-intervention behavioural outcome among adolescents about IGA.

3. To assess the impact of motivational interviewing on attitude and behavioural outcome among adolescents regarding IGA.

Present study formulated following hypothe sis to test at the level of significance $p<0.05$ : 
$\mathrm{H}_{1}$

There will be a significant effectiveness of motivational interviewing on attitude of early adolescents regarding internet gaming addiction.

$\mathbf{H}_{2} \quad$ There will be a significant effectiveness of motivational interviewing on behavioural outcome of early adolescents regard ing internet gaming addiction.

The research team have conducted a experimental research study to assessing the impact of motivational interviewing on attitude and behavioural outcome among adolescents regarding IGA at se le c ted schools of Patiala city of Punjab. The adolescents aged in between 15 to 18 years were considered as a population of the study and based on eligibility criteria the participants were recruited. Based on pr evious study findings on similar investigation, the present research has calculated total 300 sample size. We have use d probability simple sampling technique to recruit all 300 participants and then randomlyallocated to experimental and control group of investigation. Adolescents, who were willing to participate, known to English/ Punjabi language, aged in between 15 to 18 years and of any gender with minimum playing of $\geq 2$ hours per day internet games were only recruited in the study and Participants were informed about their role as a participant and requested them to sign informedconsent. Institutional ethical permission obtained well in advance and participants who have signed informed consent were introduced to study tools.

The study tools comprise with two sections, in which first sections cover the socio-demographic variables, second section comprise with Structured Attitude Rating Scale on IGA (SARS-IGA) and Structured Behavio ur al Outcome check list on IGA (SBOC-IGA). Complete tool was validated by experts from nursing fr ate rnity. The pilot study was conducted on 30 participants and the reliability of tools was computed by using $s$ using spearman brown split half method. The attitude and behavioural outcome score regarding IGA, the score was found to be 0.82 and 0.81 respectively.

RESULTS AND DISCUSSION:

The gathered data were organized in logical systematic manner andSPSS 22 version were used to analyse. The analysed data presented in following manner:

Table: 1 Frequency and percentage wise distribution of adolescents based on pre-test and post-test attitude level regarding IGA among experimental group: $\mathrm{N}-150$

\begin{tabular}{|c|c|c|c|c|c|}
\hline \multicolumn{2}{|c|}{ Level of Attitude } & \multicolumn{2}{c|}{ Pre-test } & \multicolumn{2}{c|}{ Post-test } \\
\cline { 3 - 6 } \multicolumn{2}{|c|}{} & Frequency & Percentage & \multirow{2}{*}{ Frequency } & Percentage \\
\hline \multirow{2}{*}{$\begin{array}{c}\text { Positive } \\
\text { Attitude }\end{array}$} & Experimental group & 19 & 12.66 & 115 & 76.66 \\
\cline { 2 - 6 } & Control group & 27 & 18 & 48 & 32 \\
\hline $\begin{array}{c}\text { Neutral } \\
\text { Attitude }\end{array}$ & Experimental group & 78 & 52 & 29 & 19.33 \\
\cline { 2 - 6 } & Control group & 81 & 54 & 69 & 46 \\
\hline $\begin{array}{c}\text { Negative } \\
\text { Attitude }\end{array}$ & Experimental group & 53 & 35.33 & 6 & 4 \\
\cline { 2 - 6 } & Control group & 42 & 28 & 33 & 22 \\
\hline
\end{tabular}

Table 1 stated that in experimental group prior to intervention the majority of adolescents $52 \%$ (78) we re having neutral attitude towards online gaming dependency, then $35.33 \%(53)$ we re having negative attitu de towards on line gaming (Means they were not ready to agree that they are addicted and it harm to them), and rest $12.66 \%(19)$ were having positive attitude. Then after motivational interviewing technique intervention highest number of adolescents $76.66 \%(115)$ were shown positive attitude, $19.33 \%(29)$ remain as neutral attitude and only $4 \%$ (6) adolescents found with negative attitude, whereas among control group dur ing pre test the majority of adolescents $54 \%$ (81) were havingneutral attitude towards online ga ming dependency, then $28 \%(42)$ were having negative attitude towards online gaming and rest $18 \%(27)$ were having positive attitude. In post-test highest number of adolescents $46 \%(69)$ were having neutral attitude, then $32 \%(48)$ were having positive attitude and rest $22 \%$ (33) were having negative attitude.

This is reflecting that the intervention is keeping impact to improve the attitude of adolescents regarding internet gaming addiction, but without any intervention, there were no much change noticed in the attitude of adolescents regarding internet gaming addiction. 


\section{ARTICLES}

Table:2 Frequency and percentage wise distribution of sample based on pertest and post-test behaviou ral outcome level regarding IGA:

\begin{tabular}{|c|c|c|c|c|c|}
\hline \multirow{2}{*}{\multicolumn{2}{|c|}{ Behavioural Outcome Level }} & \multicolumn{2}{|c|}{ Pre-test } & \multicolumn{2}{|c|}{ Post-test } \\
\hline & & Frequency & Percentage & Frequency & Percentage \\
\hline \multirow{2}{*}{ No IGA } & Experimental group & 1 & 0.66 & 49 & 32.66 \\
\hline & Control group & 8 & 5.33 & 12 & 8 \\
\hline \multirow{2}{*}{ Mild IGA } & Experimental group & 36 & 24 & 67 & 44.66 \\
\hline & Control group & 49 & 32.66 & 51 & 34 \\
\hline \multirow{2}{*}{$\begin{array}{c}\text { Moderate } \\
\text { IGA }\end{array}$} & Experimental group & 89 & 59.33 & 26 & 17.33 \\
\hline & Control group & 76 & 50.66 & 77 & 51.33 \\
\hline \multirow{2}{*}{$\begin{array}{c}\text { Severe } \\
\text { IGA }\end{array}$} & Experimental group & 24 & 16 & 8 & 5.33 \\
\hline & Control group & 17 & 11.33 & 10 & 6.66 \\
\hline
\end{tabular}

Presented table communicated that in experimental group prior to intervention the majority of adole scents $59.33 \%$ (89) were facing moderate level of IGA, then $24 \%$ (36) were facing mild IGA, $16 \%$ (24) we re face d severe IGA and remaining $0.66 \%$ (1) considered as not having any IGA. Then after motivation al interviewing technique intervention highest number of adolescents $44.66 \%$ (67) were shown mild IGA, 32\% (49) reflected as no IGA, $17.33 \%$ (26) were still facing moderate IGA and $5.33 \%$ (8) adolescents were facing severe IGA. Whereas in control group during pre-test the majority of adolescents $50.66 \%(76)$ were facing moderate level of IGA, then $32.66 \%$ (49) were facing mild level of IGA, $11.33 \%$ (17) faced severe level of IGA and rest $5.33 \%$ (8) we re facing no IGA. While in post-test highest number of adolescents $51.33 \%$ (77) were facing moderate level of IGA, then $34 \%$ (51) were facing mild level of IGA, 8\% (12) faced no IGA and rest all $6.66 \%$ (10) faced se ve re level of IGA.

This is reflecting that the intervention is keeping impact to improve the behavioural outcome of adolescents regarding internet gaming addiction, while without any intervention, there were no much change notic ed in the behavioural outcome of adolescents regarding internet gaming addiction.

Table: 3 Comparing Mean, Standard Deviation, Mean Difference, ' $t$ ' value and $p$-value of pre-test and post test of level of attitude regarding internet gaming addiction among experimental and control group:

\begin{tabular}{|c|c|c|c|c|c|}
\hline \multirow{2}{*}{ Two Groups } & \multicolumn{2}{|c|}{ Mean } & \multirow{2}{*}{$\begin{array}{c}\text { Mean } \\
\text { Difference }\end{array}$} & \multirow{2}{*}{ d.f. } & \multirow{2}{*}{ F Ratio } \\
\hline & Pre-test & Post-test & & & \\
\hline Experimental Group & 19 & 2.56 & 18.89 & \multirow{2}{*}{1} & \multirow{2}{*}{$10.1^{*}$} \\
\hline Control Group & 21.12 & 18.16 & 2.96 & & \\
\hline
\end{tabular}

* Significant at level of $<0.05$

Table 3 clearly stated that a comparison among experimental group and control group. It found that the mean difference of experimental group was 18.89 while in control group it was 2.96. and F ratio identified as 10.10 which reflected that among both the group, there is significant difference in terms of attitude of ad olescen ts regarding internet gaming addiction.

Therefore, the research hypothesis $\mathrm{H}_{1}$ accepted at 0.05 level of significance. This helped to stating that the provided intervention motivational interviewing found effective to improve the attitude of adolescents ab out internet gaming addiction.

Table: 4 Comparing Mean, Standard Deviation, Mean Diffe rence, ' $t$ ' value and $p$-value of pre-test and post test of level of behavioural outcome regarding internet gaming addiction among experimental and cont $\mathrm{r}$ ol group:

\begin{tabular}{|c|c|c|c|c|c|}
\hline \multirow{2}{*}{ Two Groups } & \multicolumn{2}{|c|}{ Mean } & \multirow{2}{*}{ Mean Difference } & \multirow{2}{*}{ d.f. } & \multirow{2}{*}{ F Ratio } \\
\hline & Pre-test & Post-test & & & \\
\hline Experimental Group & 18.53 & 5.73 & 12.8 & \multirow{2}{*}{1} & \multirow{2}{*}{$10.4^{*}$} \\
\hline Control Group & 19.48 & 15.21 & 4.27 & & \\
\hline
\end{tabular}

* Significant at level of $<0.05$

Present reflected a comparison among experimental group and control group. It found that the mean difference of experimental group was 12.80 while in control group it was 4.27 . and F ratio identified as 10.40 
which reflected that among both the group, there is significant difference in terms of behavioural outcome of adolescents regarding internet gaming addiction.

Therefore, the research hypothesis $\mathrm{H}_{2}$ accepted at 0.05 level of significance. This helped to stating that the provided intervention motivational interviewing found effective to improve the behavioural outcome of adolescents about internet gaming addiction.

\section{DISCUSSION}

Internet gaming dependency is increasing in rapid manner and among adolescents it is at very high prevalent. In present study the aim was to evaluate the impact of motivational interviewing on attitude and behaviou ral outcome among adolescents regarding IGA at selected schools of Patiyala city of Punjab.

In present study researcher revealed that the in experimental group prior to intervention the majority of adolescents $52 \%$ (78) were having neutral attitude towards online gaming dependency and after interven tion highest number of adolescents $76.66 \%$ (115) were shown positive attitude. While in control group in pre -te st $54 \%(81)$ and post-test $46 \%(69)$ the majority of participants have shown neutral attitude towar ds internet gaming addiction.

A similar finding was observed by a study of Lancy D'souza who have mentioned that among Indian stude nts the majority of samples $54.3 \%$ are showing average level of PUBG addiction, while $6.2 \%$ found definitely addicted. Here the average category of addiction is similar with mild level of addiction and definitely addiction is equal to severe addiction in this present study.(10) Similarly a study by Adithya Thakur et al has stated that $55 \%$ of participants are found with mild internet gaming addicted.(11)

Further in experimental group prior to intervention the majority of adolescents $59.33 \%$ (89) were facing moderate level of IGA, then after motivational interviewing technique intervention highest number of adolescents $44.66 \%$ (67) were shown mild IGA. Whereas in control group during pre -test the majority of adolescents $50.66 \%$ (76) were facing moderate level of IGA, and in post-test also highest number of adolescents $51.33 \%$ (77) were facingmoderate level of IGA.

These findings supported by a study of R. Publendhi who's research findings were said that $74 \%$ of participants are facing little aggressive nature due to PUBG game addiction.(12) Similarly Studyby Aditya Thakur et al has stated that majority $86.5 \%$ of participants have shown behavioural outcome issues. (11)

Analysed data have found that the mean difference of experimental group was 18.89 while in control group it was 2.96. and $\mathrm{F}$ ratio identified as 10.10 which reflected that among both the group, there is significant difference in terms of attitude of adolescents regarding internet gaming addiction. Similarly, the mean difference of experimental group was 12.80 while in control group it was 4.27 . and F ratio identified as 10.40 which reflected that among both the group, there is significant difference in terms of behavioural outcome of adolescents regarding internet gaming addiction. These finding suggested that the provided motivational interviewing technique is effective to enhance attitude and behavioural outcome of IGA victims.

One study by Adeline stated in their result that about half the sample reported at le ast a $50 \%$ reduction in alcohol use and slightly more than one in five reported no alcohol use at six-month follow-up with motivational interviewing. They mentioned that MI has been shown to be effective for the management of problem drinking among college students, and homeless persons. They found no evidence of differential efficacy of one-on-one vs group-delivered MI over a nurse-led intervention in reducing alcohol drinking.(13) In light of the aftereffect of this investigation, there is need to modify the attitude and behavioural outcome of adolescents. The motivational interviewing is a worth therapy to modify the attitude and behavioural outcome of adolescents.

\section{CONCLUSION:}

Internet gaming addiction among all age group and especially among adolescent is increasing day by day. The most common symptoms of such addicted person is behavioural deterioration which are similar like substance abuse. The IGA has been added in disease classification, which described its importance. Hence, it is esse $n$ tial to investigate towards this line of area.

The study results revealed that Motivational Interviewing (MI) has positive impact to e $n$ hance attitude and behavioural outcome among adolescents having issue with internet gaming addiction.

\section{ACKNOWLEDGEMENT:}

We are grateful to the All-Mighty God for this great blessing throughout this endeavour.

Any accomplishment requires the effort of many people. We feel it is a great privilege to express our heartfe lt thanks and gratitude to all who directly or indirectly have given valuable guidance and timely suggestion throughout this dissertation work. Quality always makes difference through its generosity, richness, kin d ness and intelligence.

We express our sincere thanks to all the Experts in the field of mental health Nursing for validating the content of the tool and provided valuable suggestions and guiding in validating the tool. 


\section{REFERENCES:}

1. Achab S, Simon O, Martinotti G, Zullino D, Khazaal Y. Textbook of Addiction Treatment: Inte rnatio nal Perspectives. Textb Addict Treat Int Perspect. 2015;1499-513.

2. Shahnaz I, Karim AKMR. The Impact of Internet Addiction on Life Satisfaction and Life Engagement in Young Adults. Univers J Psychol. 2014;2(9):273-84.

3. Qin YS. a Study of Internet Addiction Among Students of Sekolah. 2011.

4. Przybylski AK, Weinstein N, Murayama K. Internet gaming disorder: Investigating the clinical relevance of a new phenomenon. Am J Psychiatry. 2017;174(3):230-5.

5. Park Chyun, Chun JW, Cho H, Kim DJ. Alterations in the connection topology of brain structural networks in Internet gaming addiction. Sci Rep. 2018;8(1): 1-9.

6. Romano M, Osborne LA, Truzoli R, Reed P. Differential Psychological Impact of Internet Exposure on Internet Addicts. PLoS One. 2013;8(2).

7. Nnenna V. Internet Addiction, Neuroplasticity and Education. 2020;(February).

8. Osilla KC, Paddock SM, Leininger TJ, D'Amico EJ, Ewing BA, Watkins KE. A pilot study comparing inperson and web-based motivational interviewing among adults with a first-time DUI offense. Addict Sci Clin Pract. 2015;10(1):1-11.

9. Farahani M, Alavi SS, Bafghi MM, Alamuti SE, Mohammadi M, Taghavi Z. Psychological factors including demographic features, mental illnesses, and personality disorders as predictors in internet addiction disorder. Iran J Psychiatry. 2018;13(2):104-11.

10. Souza LD, Dolma P. Extent of PUBG Addiction among Indian and Tibetan Students : A Comparative Study. Int J Indian Psychol. 2019;7(2):482-8.

11. Thakur A, Peepre K, Vaswani A, Gupta K, Verma A, Singh D, et al. Internet addiction, behavioural aspects, and health related problemsassociated with it: a cross sectional study among engineering students of Jabalpur district. Int J Res Med Sci. 2017;6(1): 253.

12. Pugalendhi R, d sjmp. Impact study of pubg game addiction on consumerculture of chennai urban students. Int J Sci Technol Manag. 2019;8(11):57-61.

13. Nyamathi A, Steven Shoptaw, Cohen A, Greengold B, Kamala Nyamathi. Effect of motivational interviewing on reduction of alcohol use. Drug Alcohol Depend. 2010;107(1):23-30. 